\title{
A New Alkali-Silica Reaction (ASR) Mitigation Technology - Part I: Comparing with Li, Ca, Al Salts, and Densified Silica Fume
}

\author{
Frank Ong ${ }^{1}$, Michael Myers ${ }^{2}$, Thomas Vickers ${ }^{3}$, Jacki Atienza ${ }^{4}$, Lesley Ko ${ }^{5}$ and Paul \\ Seiler $^{6}$ \\ ${ }^{1}$ Master Builders Solutions - Admixture Systems N.A. 23700 Chagrin Blvd, Beachwood, Ohio, \\ 44122, United States, frank.ong@mbcc-group.com \\ ${ }^{2}$ Master Builders Solutions- Admixture Systems N.A. 23700 Chagrin Blvd, Beachwood, Ohio, \\ 44122, United States, michael.myers@mbcc-group.com \\ 3 Master Builders Solutions - Admixture Systems N.A. 23700 Chagrin Blvd, Beachwood, Ohio, \\ 44122, United States, thomas.vickers@mbcc-group.com \\ ${ }^{4}$ Master Builders Solutions - Admixture Systems N.A. 23700 Chagrin Blvd, Beachwood, Ohio, \\ 44122, United States, jacki.atienza@mbcc-group.com \\ ${ }^{5}$ Master Builders Solutions - Admixture Systems N.A. 23700 Chagrin Blvd, Beachwood, Ohio, \\ 44122, United States, lesley.ko@mbcc-group.com \\ ${ }^{6}$ Master Builders Solutions - Admixture Systems N.A. 23700 Chagrin Blvd, Beachwood, Ohio, \\ 44122, United States, paul.seiler@mbcc-group.com
}

\begin{abstract}
Alkali-silica reaction (ASR) is a major concrete durability problem. The occurrence of ASR results in significant maintenance and reconstruction costs to concrete infrastructures all over the world. Ever since Stanton (1940) discovered the expansive characteristics of ASR in 1940, there has been much speculation as to the cause and actual mechanism of expansion. Current market solutions are not always sustainable, such as hauling non-reactive aggregates or fly ash from long distance; or use of Li-based chemical admixture that is facing challenge of raw material's availability. The current article will present a patent pending technology which provides a commercial solution for mitigating the ASR. The ASR mitigating effect of this technology is compared with lithium, calcium, and aluminum salts, and densified silica fume.
\end{abstract}

Keywords: Alkali-Silica Reaction (ASR), Durability, Silica Fume, Metakaolin, $\mathrm{LiNO}_{3}, \mathrm{Ca}\left(\mathrm{NO}_{3}\right)_{2}$, $\mathrm{Ca}\left(\mathrm{NO}_{2}\right)_{2}, \mathrm{Al}\left(\mathrm{NO}_{3}\right)_{3}$, Expansion, Slurry, Solution.

\section{Introduction}

Since Stanton (1940) demonstrated that reaction between high-alkali cements and certain aggregates could cause disintegration of concrete, a large amount of research has focused on the alkali aggregate reaction. An annotated bibliography containing over 1300 references pertinent to the phenomenon of alkali silica reaction (ASR), was compiled by Diamond (1992). ASR has remained a subject of much research and discussion because of the necessity of employing marginal aggregates in many areas, as well as the limited availability of low alkali cement, class F fly ash, slag, and lithium. Szeles et al. (2017) estimated that by 2030, the supply of fly ash in the United States will be approximately 14 million tons, but the demand will exceed 35 million tons. Lithium-based chemical admixtures face limited raw material availability and 
rising price. Tesla and other electric-vehicle makers dominate lithium consumption, a lightweight element that some call "white petroleum" for its use in lithium-ion batteries that power electric cars. 'In order to produce half a million cars a year... we would basically need to absorb the entire world's lithium-ion production,' Elon Musk said in March 2016 according the Wall Street Journal (2016).

Densified silica fume has been used to increase ASR resistance. Due to low volume demand, concrete manufacturers do not normally install a silo for densified silica fume. The two main issues of densified silica fume are: (1) it might cause ASR due to agglomeration (Pettersson 1992), and (2) densified silica fume in bags are difficult use in concrete manufacturing. Clearly, the concrete industry is looking for alternative chemical admixtures, which are easily dispensed into a central mixer or concrete truck in ready mix concrete or precast plants, for mitigating ASR.

Six pumpable products, which are three salt solutions and three slurries were selected in this study. The three salt solutions are Calcium Nitrate $\left(\mathrm{Ca}\left(\mathrm{NO}_{3}\right)_{2}\right)$, Calcium Nitite $\left(\mathrm{Ca}\left(\mathrm{NO}_{2}\right)_{2}\right)$, and Aluminum Nitrate $\left(\mathrm{Al}\left(\mathrm{NO}_{3}\right)_{3}\right)$. The three pumpable slurries are based on densified silica fume, metakaolin, and Z silica fume (a by product from zirconia oxide manufacture). The technology of manufacturing these slurries is patent pending. A screening test method was developed based on ASTM C1567 (2018) to evaluate the ASR mitigating effects of these six products.

\section{Experimental}
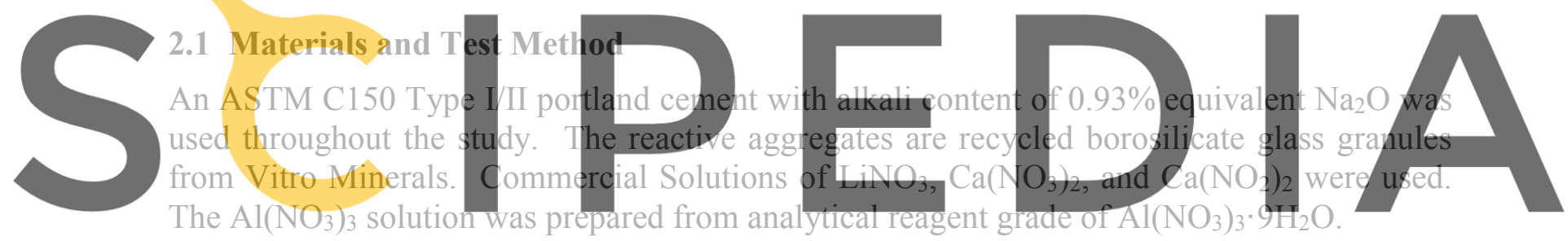

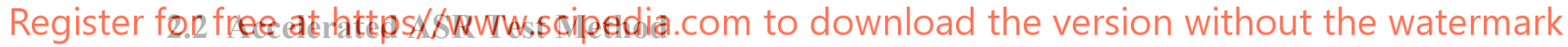

To evaluate the ASR mitigation effects of the selected materials, an accelerated test method based on ASTM C1567 (2018) was developed. The key for developing an accelerated ASR test method is to determine the pessimum amount reactive aggregate (borosilicate granules) in the mortar mixture. The pessimum amount of borosilicate is about $25 \%$ of total fine aggregate, which caused the maximum ASR expansion under the current test condition. Therefore, the screening test for evaluating potential candidates for ASR mitigation was designed as follows:

- Mortar with pessimum amount of reactive aggregate (25\% borosilicate).

- Follow the ASTM C1567 test procedure.

- The expansion results are an average of four measurements.

\section{Results and Discussion}

\subsection{Effects of $\mathrm{LiNO}_{3}, \mathrm{Ca}\left(\mathrm{NO}_{3}\right)_{2}, \mathrm{Ca}\left(\mathrm{NO}_{2}\right)_{2}$, and $\mathrm{Al}\left(\mathrm{NO}_{3}\right)_{3}$ on $\mathrm{ASR}$}

The alkali silica reaction (ASR) is primarily one of $\mathrm{OH}^{-}$ions rather than of alkali cations; nevertheless, the latter are of critical importance. Both sodium and potassium ions cause distress; lithium apparently not, and its presence tends to inhibit distress. In an attempt to find 
a compound that would effectively inhibit ASR, McCoy and Caldwell (1951) carried out a vast number of mortar tests with a representative selection of many types of possible additive materials. The most significant facts that emerged from this study was that lithium compounds ( $\mathrm{LiCl}, \mathrm{Li}_{2} \mathrm{CO}_{3}, \mathrm{LiF}, \mathrm{Li}_{2} \mathrm{SiO}_{3}, \mathrm{LiNO}_{3}$, and $\mathrm{Li}_{2} \mathrm{SO}_{4}$ ), in some unexplained way, reduced mortar expansion. Even almost insoluble lithium salts, such as LiF, seemed to be beneficial. Ong (1993) demonstrated that these insoluble lithium salts, such as $\mathrm{LiF}$ and $\mathrm{Li}_{2} \mathrm{CO}_{3}$ were quickly converted to $\mathrm{LiOH}$ in pore solution of cement paste. Due to its high solubility in water, $\mathrm{LiNO}_{3}$ has been commercially used as a chemical admixture for mitigating ASR. The mechanisms of ASR mitigating by $\mathrm{LiNO}_{3}$ was recently studied by Feng et al. (2010) and Guo et al. (2019). The formation of Li-Si crystal (Feng 2010) or Li-Si amorphous structure (Guo 2019) act as barrier surface on the reactive aggregate surface and prevent ASR.

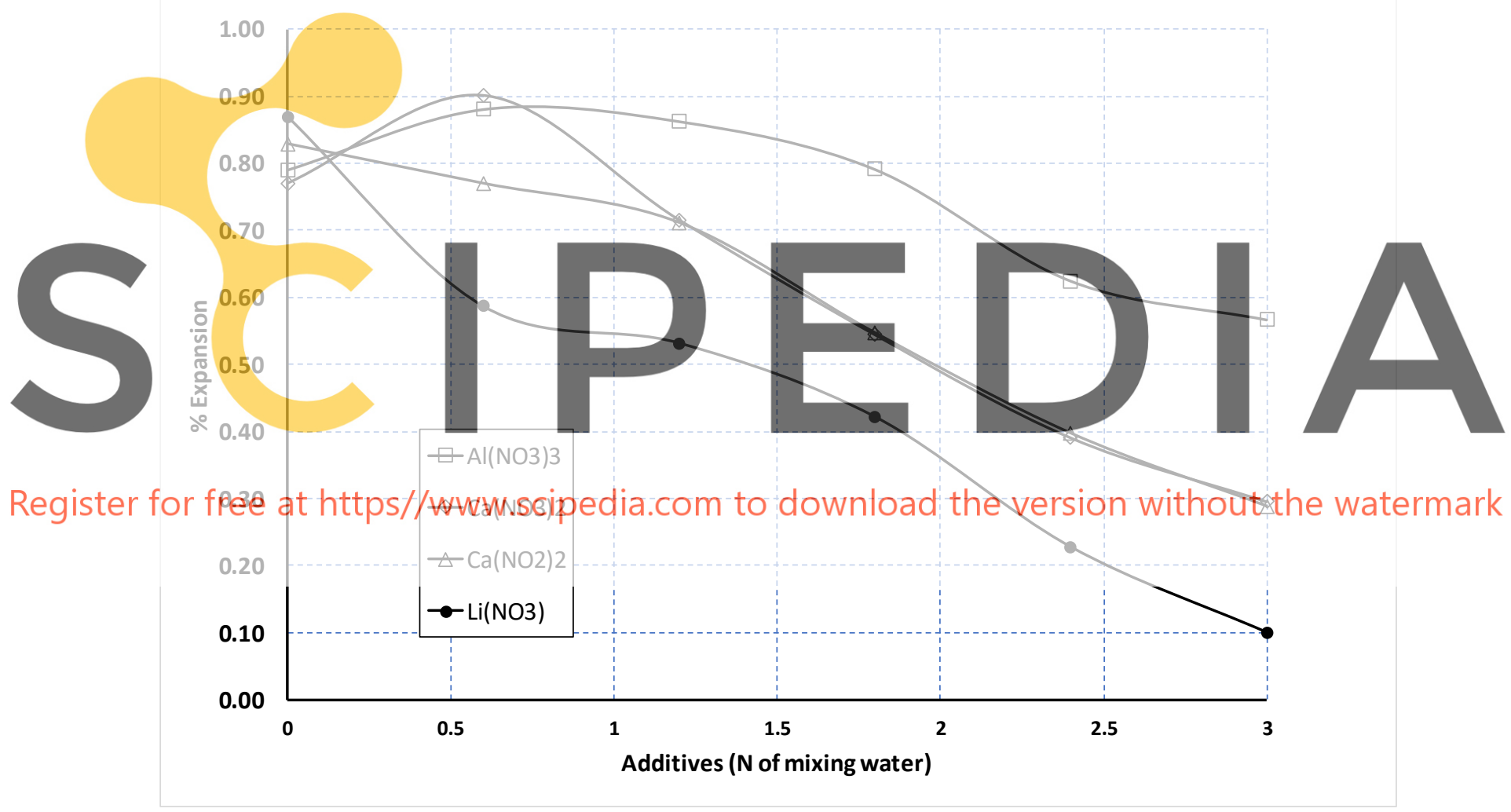

Figure 1. The comparison of ASR mitigating effects of $\mathrm{LiNO}_{3}, \mathrm{Ca}\left(\mathrm{NO}_{3}\right)_{2}, \mathrm{Ca}\left(\mathrm{NO}_{2}\right)_{2}$, and $\mathrm{Al}\left(\mathrm{NO}_{3}\right)_{3}$.

The role of calcium ions in ASR have been investigated and debated for many years. Powers and Steinour (1955) suggested that ASR gel with a low-calcium content was expansive, while ASR gel with a high-calcium content was not expansive. Hudec and Banahene (1993) indicated that calcium ions mitigated ASR. Concrete with some free calcium ions in pore solution did not expand as much as one without. On the other side, many studies (Kawamura et al., 1998, Aquino et al., 2001, and Feng et al., 2010) suggested that calcium ions are vital for 
deleterious ASR expansion to occur. Without calcium ions, silica dissolves by $\mathrm{OH}^{-}$and remains in solution (Thomas 1998).

Even though there are limited studies directly on the effect of aluminum on ASR, a good review on the beneficial effects of aluminum in mitigating ASR was provided by Rajabipour $e t$ al. (2015). The proposed explanations for Al benefits are:

- Reducing silica dissolution by $\mathrm{Al}$ adsorption on the surface of reactive aggregate.

- Removing $\mathrm{OH}^{-}$ions by the formation of C-A-S-H.

- Removing $\mathrm{Ca}(\mathrm{OH})_{2}$ to form calcium aluminate phase.

The above hypotheses were further investigated by studying the effect of $\mathrm{Al}(\mathrm{OH})_{3}$ on ASR expansion with ASTM C1293 concrete prisms (Szeles et al., 2017). It was found that the replacement of $20 \%$ cement with $\mathrm{Al}(\mathrm{OH})_{3}$ significantly reduced silica dissolution and prevented ASR expansion.

The ASR mitigating effects of lithium, calcium and aluminum salt solutions were compared at five dosages: $0.6,1.2,1.8,2.4$, and $3.0 \mathrm{~N}$ of the initial mixing water. Figure 1 compares the ASR mitigating effects with different salts, at 14-day expansion as a function of additive normality of initial mixing water. The results in Figure 6 are summarized as following:

1. $\mathrm{LiNO}_{3}$ solution has the most ASR mitigating effect in term of expansion reduction, among the four salt solutions tested. The addition of $0.6 \mathrm{~N}$ of $\mathrm{LiNO}_{3}$ significantly reduced ASR expansion, however this dosage was not enough to suppress the ASR. The 14-day expansion was still 0.59\%. With increasing dosage of $\mathrm{LiNO}_{3}$, ASR expansion was
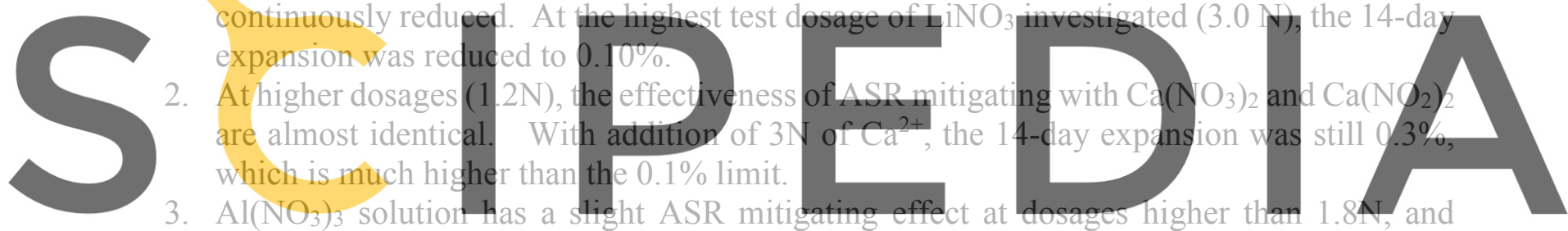

causes increased ASR expansion at lower dosages.

Register for free at https//www.scipedia.com to download the version without the watermark 3.2 Effects of Silica Fume and Metakaolin Slurries on ASR

Silica fume is an ultrafine powder collected as a by-product of the silicon and ferrosilicon alloy production with a very light bulk density of $130 \mathrm{~kg} / \mathrm{m}^{3}$. Densified silica fume is produced by treating silica fume to increase the bulk density up to a maximum of about 400 to $720 \mathrm{~kg} / \mathrm{m}^{3}$. This increase in bulk density is usually accomplished by tumbling the silica fume particles in a silo, which causes surface charges to build up. One harmful consequence of the densification is that significant contents of undispersed grains of the order of several hundred microns are found in cementitious materials treated with densified silica fume (Diamond 1997). The grain can react with $\mathrm{OH}^{-}$which may give rise to ASR distress. The agglomeration of silica fume particles is illustrated in the low and high magnification SEM images shown in Figure 2. At low magnifcation, the silica fume was clustered in grains of a few microns to several hundred microns, as shown in the left side image in Figure 2. The original size of the silica fume particles were in the range of a few nanometers to several hundred nanometers, as shown in the high magnification image on the right side of Figure 2. 

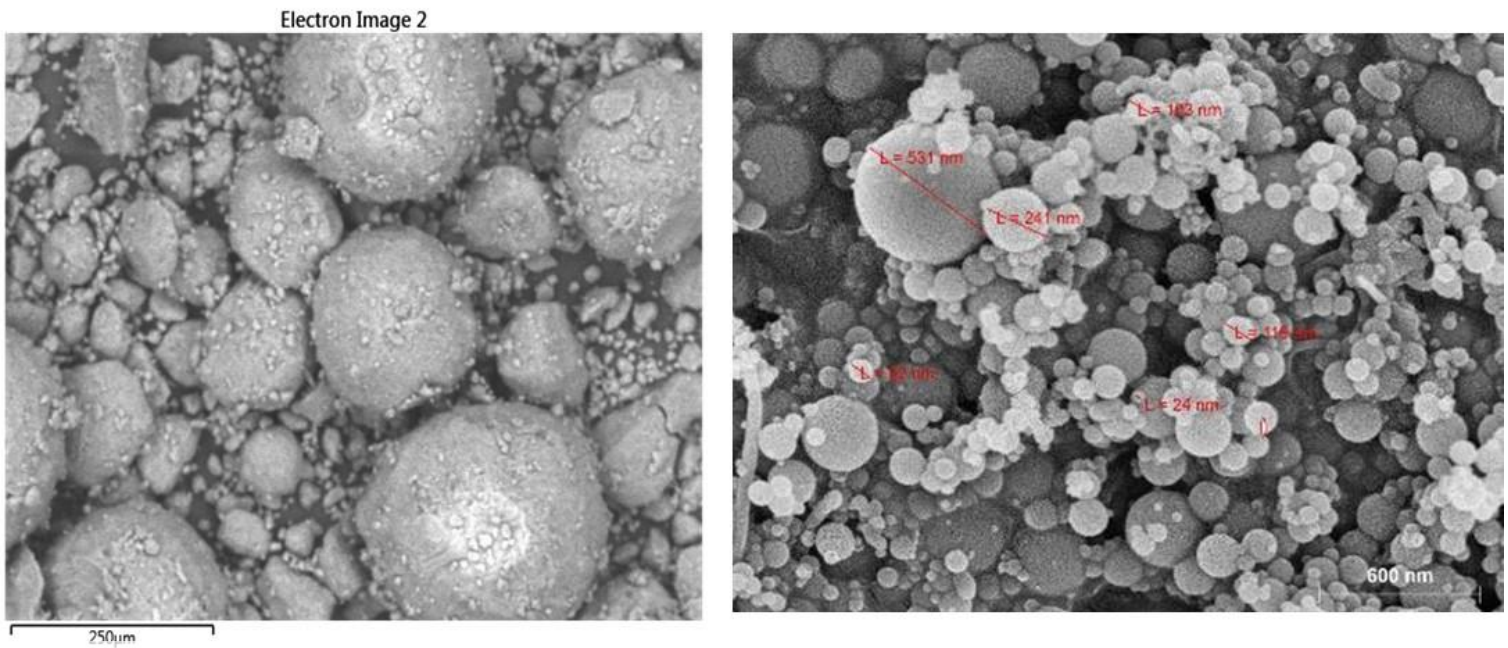

Figure 2. The SEM images of densified silica fume with low and high magnifications.
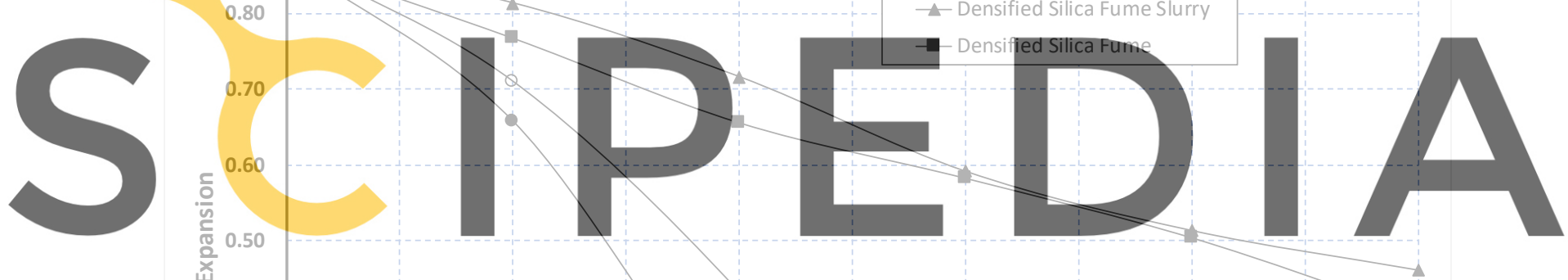

Register for fofre at https//Awww-scipedia.com to download the version without the watermark

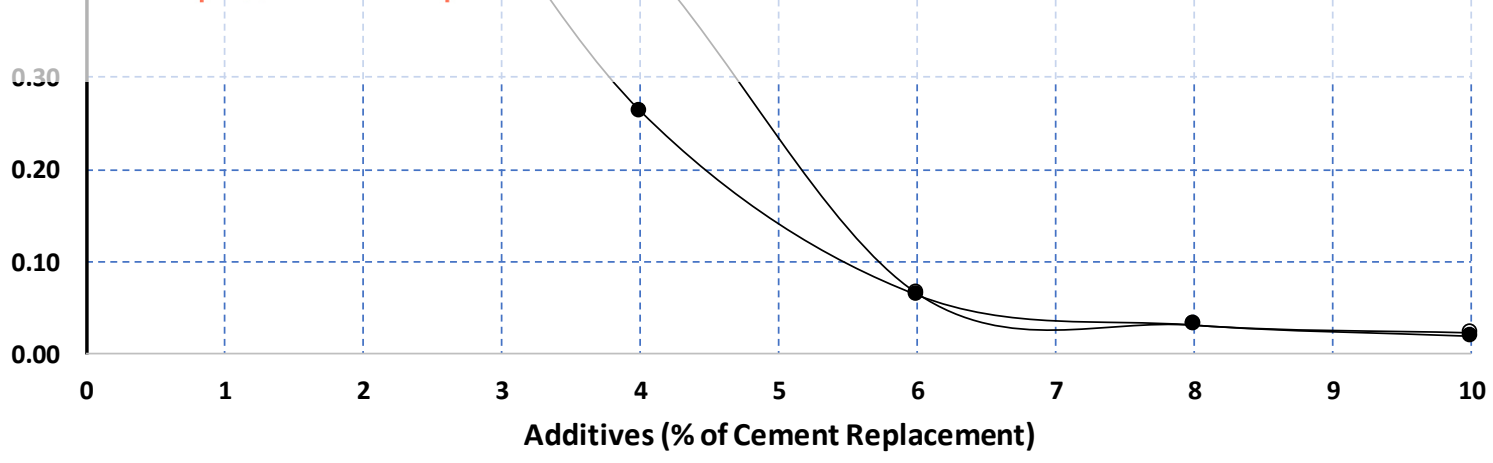

Figure 3. The comparison of ASR mitigating effects of different slurries and densified silica fume.

A direct comparison of the ASR mitigating effects of densified silica fume and the three slurries, at 14-day expansion, as a function of additive percentage by weight of cement replacement, are compiled in Figure 3. The results in Figure 3 are summarized as following: 
1. Densified silica fume has the lowest ASR mitigating effect in term of expansion reduction, among the four products tested.

2. Converting densified silica fume to a slurry form only slightly improves the ASR mitigating effect.

3. Metakaolin and $\mathrm{Z}$ silica fume slurries have almost identical ASR mitigating effect. When the dosages of both slurries were increased to $6 \%$ (dry basis), the ASR was almost stopped, resulting in only $0.07 \%$ expansion at 14 .

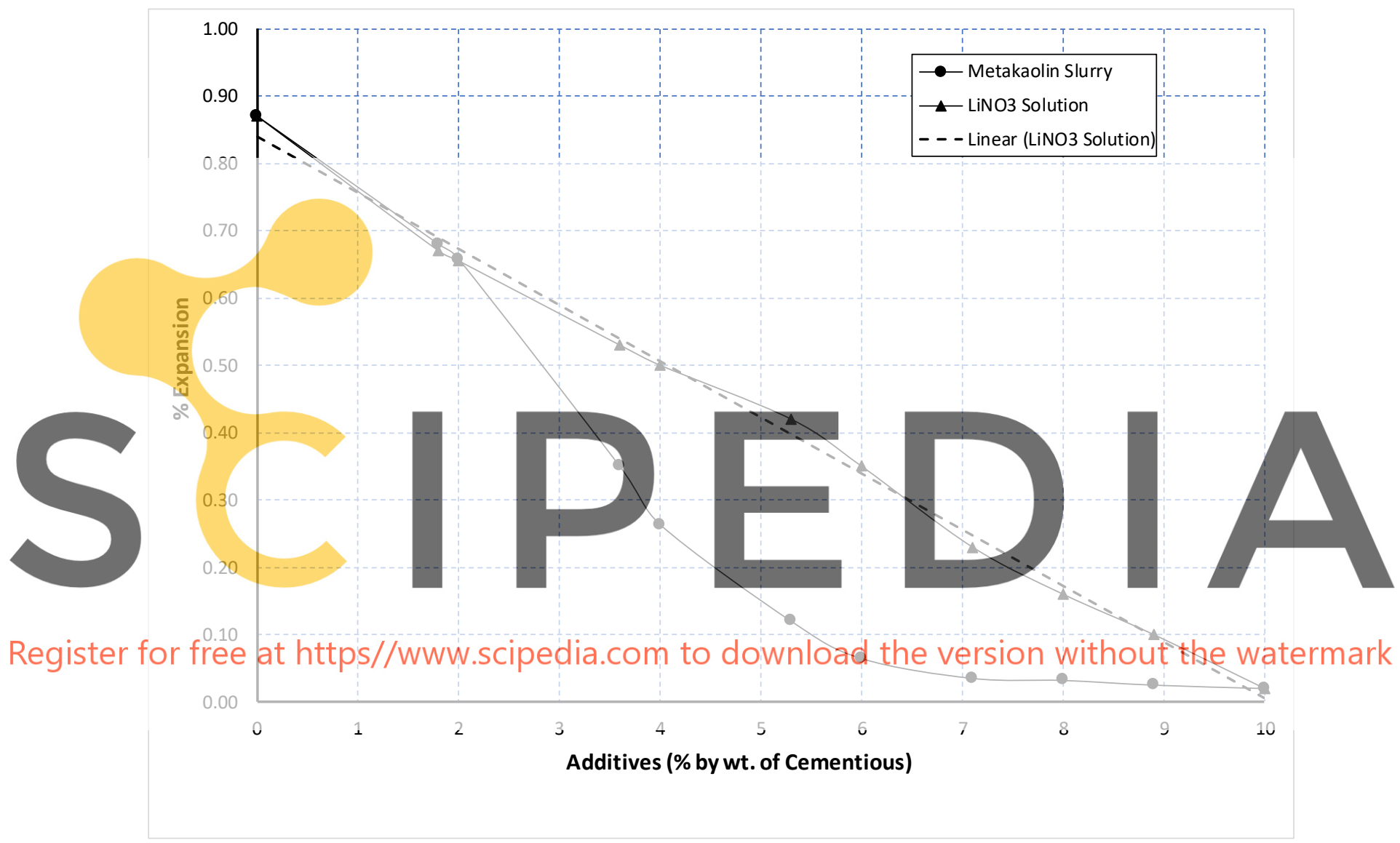

Figure 4. The comparison of ASR mitigating effects of $\mathrm{LiNO}_{3}$ solution and metakaolin slurry.

The ASR mitigating effects of $\mathrm{LiNO}_{3}$ solution and metakaolin slurry are compared in Figure 4. Dosages are expressed as percentage of total cementitious materials on a dry basis. The results in Figure 4 are summarized as following:

1. At low dosages (less than $2 \%$ ), both $\mathrm{LiNO}_{3}$ solution and metakaolin have similar ASR mitigating effect.

2. The reduction of ASR expansion by $\mathrm{LiNO}_{3}$ solution is increased almost linearly with increasing dosage. To achieve a 14-day expansion less than $0.1 \%$, the dosage of $\mathrm{LiNO}_{3}$ exceeded $8.9 \%$ by weight of cement in the current testing condition, whose soak solution is not buffered with $\mathrm{LiNO}_{3}$. 
3. At a dosage greater than $2 \%$, the reduction in ASR expansion by the metakaolin slurry is accelerated away from linear. A metakaolin dosage of $6 \%$ by weight of total cementitious materials is enough to suppress the ASR.

\section{Conclusions}

Due to a critical shortage of lithium raw material and difficulty with using densified silica fume, an effort was made to develop an alternative chemical admixture for mitigating ASR. Six dispensible materials were tested as potential candiates to replace $\mathrm{LiNO}_{3}$ and densified silica fume. Based on the results of ASTM C 1567 expansions of mortar bars, the following conclusions can be made:

- For salt solutions, $\mathrm{LiNO}_{3}$ is the best choice for ASR mitigating.

- Solutions of $\mathrm{Ca}\left(\mathrm{NO}_{3}\right)_{2}$ and $\mathrm{Ca}\left(\mathrm{NO}_{2}\right)_{2}$ have the same ASR mitigating effect, but are not effective enough to stop ASR. Therefore, $\mathrm{Ca}\left(\mathrm{NO}_{3}\right)_{2}$ or $\mathrm{Ca}\left(\mathrm{NO}_{2}\right)_{2}$ solution itself can't not be the candidate to replace $\mathrm{LiNO}_{3}$ as chemical admixture for mitigating ASR.

$\mathrm{Al}\left(\mathrm{NO}_{3}\right)_{3}$ solution has a weak ASR mitigating effect and a negative effect on workability. It will not be recommended as chemical admixture for mitigating ASR.

The densified silica fume slurry has only slighly better ASR mitigating effect than densified silica fume. The slurry manufacturing procedure was unable to break-down clustered silica fume particles.

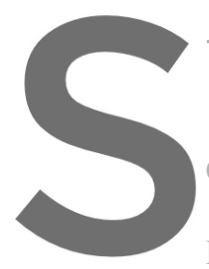
Both pumpable slum effect.

ORCID
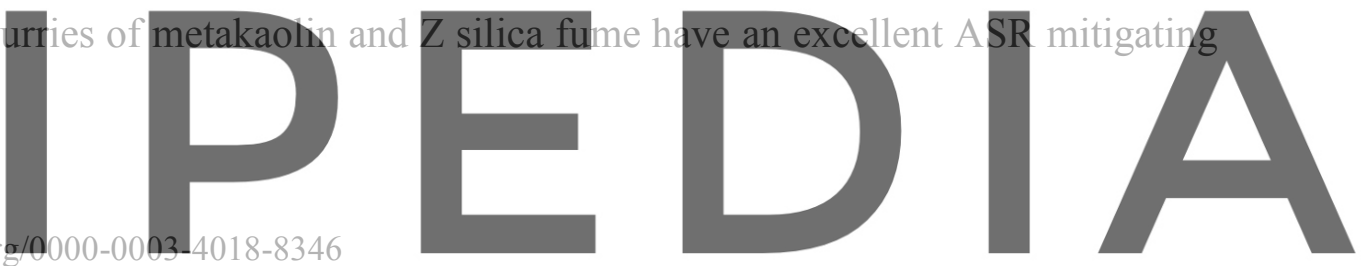

Register forforengest https//www.scipedia.com to download the version without the watermark

Aquino, A., Lange, D.A. and Olek J. (2001). The influence of mekakaolin and silica fume on the chemistry of alkali-silica reaction products, Cement \& Concrete Composites, 23, pp. 485-493, 2001.

ASTM C1567 (2018). Standard test method for determining the potential alkali-silica reactivity of combinations of cementitious materials and aggregate (accelerated mortar-bar method), Annual Book of ASTM Standards, Vol. 04.02, pp. 816-821, 2018.

Diamond, S. (1997). Alkali silica reaction - some paradoxes, Cement and Concrete Composites, pp. 391-401, 1997.

Diamond, S. (1992). Alkali aggregate reactions in concrete: an annotated bibliography 1939-1991, SHRPC/UWP-92-601, 465 pages, 1992.

Feng, X., Thomas, M.D.A., Bremner, T.W., Folliard, K.J. and Fournier, B. (2010). New onservations on the mechanism of lithium nitrate against alkali silica reaction (ASR), Cement and Concrete Research 40 pp. 94$101,2010$.

Guo, S., Dai, Q. and Si, R. (2019). Effect of calcium and lithium on alkali-silica reaction kinetics and phase development, Cement and Concrete Research 115, pp. 220-229, 2019.

Hudec, P.P. and Banahene, N.K. (1993). Chemical treatments and additives for controlling alkali activity, Cement \& Concrete Composites 15, pp. 21-26, 1993.

Kawamura, M., Noriyuki, A. and Terashima, T. (1998). Mechanisms of suppression of ASR expansion by fly ash from the view point of gel composition, The Sidney Diamond Symposium, pp. 277-284, 1998.

McCoy, W.J. and Caldwell, A.G. (1951). New approach to inhibiting alkali-aggregate expansion, Journal of ACI, May 1951, Vol. 12, No. 1, pp. 96-103. 
Ong, S. (1993). Studies of steam curing and alkali hydroxide additions on pore solution chemistry, microstructure and alkali silica reations, Ph.D. thesis, Purdue University, 1993.

Pettersson, K. (2017). Effects of silica fume on alkali-silica expansion in mortar specimens, Cement and Concrete Research, 22(1), pp. 15-22, 1992.

Powers, T.C. and Steinour, H.H. (1955). An interpretation of some published researches on the alkali-aggregate reaction Part I, the chemical reactions and mechanism of expansion, ACI Journal, Vol. 26, No. 6, pp. 497$516,1955$.

Rajabipour, F., Giannini, E., Dunant, C., Ideker J.H. and Thomas, M.D.A. (2015). Alkali-silica reaction: current understanding of the reaction mechanisms and the knowledge gaps, Cement and Concrete Research 76 pp. 130-146, 2015.

Stanton, T.E. (1940). Expansion of concrete through reaction between cement and aggregate, Proceedings, ASCE, Vol. 66, 1940, pp. 1781-1811.

Szeles, T., Wright, J., Rajabipour, F. and Stoffels, S. (2017). Mitigation of alkali-silica reaction by hydrated alumina, Journal of the Transportation Research Board, No. 2629, 2017, pp. 15-23.

Thomas, M.D.A. (1998). The role of calcium in alkali-silica reaction, The Sidney Diamond Symposium, pp. 325 331,1998

Wall Street Journal. (2016). https://www.wsj.com/articles/how-lithium-defied-the-global-commodities-rout$1462450790,2016$.
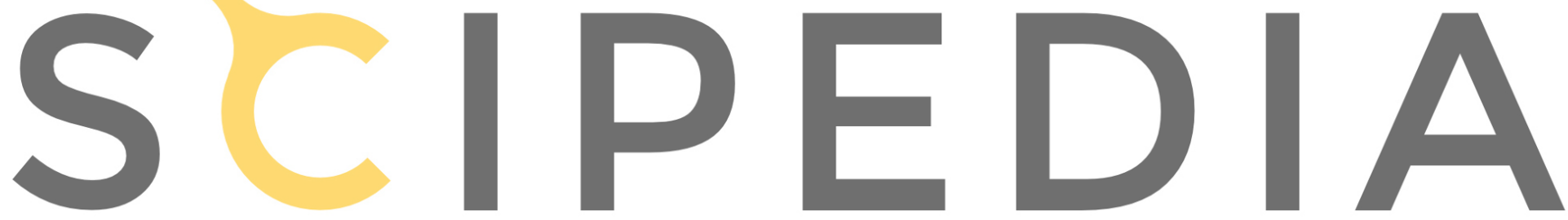

Register for free at https//www.scipedia.com to download the version without the watermark 